\title{
The Impacts Of Cooperative Learning On Anxiety And Proficiency In An EFL Class
}

Ornprapat Suwantarathip, Bangkok University, Thailand Saovapa Wichadee, Bangkok University, Thailand

\begin{abstract}
The purposes of this study were to examine the effectiveness of cooperative learning approach in reducing foreign language anxiety and to investigate its impact on language proficiency of 40 sophomore students enrolled in EN 211 course in the second semester of 2009 academic year at Bangkok University. Three instruments employed were the standardized Foreign Language Classroom Anxiety Scale (FLCAS) (Horwitz, Horwitz, \& Cope, 1986), two proficiency tests covering reading and writing skills, and a semi-structured interview. The pre- and post-scores from the questionnaire and the tests of the group were calculated for descriptive statistics and compared using a paired sample t-test measure. It was found that the students' top five sources of language classroom anxiety and overall language anxiety were significantly decreased. In addition, they obtained higher language proficiency scores for the post-test than the pre-test at the significance level of .001 after learning through this approach. The students also had a favorable attitude toward cooperative learning as a whole.
\end{abstract}

Keywords: Foreign Language Learning Anxiety, Cooperative Learning

\section{INTRODUCTION}

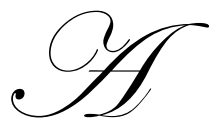

nxiety in the classroom is considered a negative factor that lessens the learner's proficiency due to the fact that under the anxious situation, it's difficult to think clearly. According to MacIntyre (1995: 96), anxiety can create a divided attention scenario for anxious students; they are focused on both the task at hand and their reactions to it. For example, when responding to a question in a class, the anxious student is focused on answering the teacher's question and evaluating the social implications of the answer while giving it. As a result, they cannot do a good job in learning. Meanwhile, students with low proficiency of English tend to have more anxiety because studying English language might be perceived as difficult for them. That they feel worried and anxious in language classroom can eventually lead them to dislike - and a lack of enthusiasm learning. The important role of language anxiety in foreign language learning has been demonstrated in several studies showing a negative correlation between high levels of anxiety and language achievement (Saguanpong, 2007; Yu-ching \& Wu, 2004; Kondo \& Yang, 2003). Knowing this, many pieces of research were done to find out a way to help students reduce anxiety. Take, for example, a study conducted by Worde (2003) who investigated students' perspectives on Foreign language anxiety and whose finding revealed that a factor students believed may help to reduce anxiety included a sense of community. When students felt alone with no friends, they were "more self-conscious. Several participants mentioned that working in groups or having study partners appears to reduce anxiety for some as it created a relaxing classroom environment.

During the past decade, "Cooperative Learning" seemed to attract a lot of attention and became popular. This conceptual approach is based on a theoretical framework that provides general principles on how to structure cooperative learning activities in a specific subject area. According to Johnson (2005), cooperative learning is a teaching strategy in which small teams, each with students of different levels of ability, use a variety of learning activities to improve their understanding of a subject. Each member of a team is responsible not only for learning what is being taught, but also for helping teammates learn, thus creating an atmosphere of achievement. Students work through the assignment until all group members successfully understand and complete it. Teachers can use this approach to stimulate students to acquire the knowledge, as well as create interpersonal and team skills. Each 
student has a different background and ability in English, which he or she can bring to the group, so group members can complement each other's strengths and weaknesses in English. For example, one student might have a strong vocabulary that can supply students with a solid background in grammar. Furthermore, poor students will benefit from interaction with better ones, and good students will feel proud that they play an important role in helping their weaker classmates. Johnson, \& Johnson (1995) state that cooperative learning approach creates a supportive learning setting; it decreases competitiveness and individualism but increases opportunities to actively construct or transform the knowledge among students. By working in groups, students have more opportunities to talk and share ideas so they can see how their peers think and create new ideas. In addition, discussing, creating, and thinking in a group, rather than in a whole class context, can provide a less anxiety-producing context. In such an atmosphere, students may feel more comfortable to try out new ideas. Therefore, a cooperative learning environment is believed to reduce anxiety and provide more opportunities for students to produce language (Kagan, 1994).

Many pieces of research have supported the effectiveness of cooperative learning in EFL classes so far. In Nakahashi's study (2007), he used structured cooperative learning activities to reduce language anxiety of freshmen students in Akita University by providing a nonthreatening, supportive environment that led to language skills development. The results revealed that the students' learning anxiety reduced and their language proficiency scores improved significantly after the learning. To support its effectiveness in terms of language improvement, the results of many studies indicate that cooperative learning approach could help develop students' English proficiency, such as Somapee (2002), Seetape (2003) and Lapsopa (2005). The post-test score, after learning English with cooperative learning activities, was higher than the pre-test score at the .05 level of significance. Apart from the higher scores that students gained, they had a positive attitude toward this kind of learning.

The second-year students were chosen in this study because of the contents in EN211 that are rather difficult. From past experience, students with low proficiency of English enrolled in this course and were not able to catch up with others in class. Many of them developed a negative attitude toward studying English and they often cut the class. To solve this problem, the cooperative learning approach was of interest to the researcher due to its positive outcomes as mentioned earlier. The study was therefore conducted to see if it was effective in changing a classroom atmosphere to have less anxiety and in producing higher achievement. The research findings, therefore, enable me to understand my students' learning better, find an effective way to help create conditions that allow students more opportunities to communicate in the target language in a relaxed, supportive environment, as well as enhance my ability to teach English.

\section{OBJECTIVES OF THE RESEARCH}

- $\quad$ To compare the mean scores of learning anxiety before and after learning with cooperative learning activities

- $\quad$ To compare the mean scores of english proficiency before and after learning with cooperative learning activities

- $\quad$ To examine the students' opinions toward cooperative learning

\section{RESEARCH METHODOLOGY}

\subsection{Research Design}

This study employed the one group pre-test, post-test design. The data were collected from one section containing 40 students enrolled in a required EN 211 course of three credits in the first semester of 2009 academic year through cluster sampling since students were already assigned to their sections.

\subsection{Instruments}

Three instruments were used to assess the effectiveness of the cooperative learning for reducing students' language anxiety. The first one was the Foreign Language Classroom Anxiety Scale (FLCAS) (Horwitz, Horwitz, \& Cope, 1986). The FLCAS was a standardized 33-item survey that assesses levels of anxiety related to three areas: (1) communication apprehension, (2) test anxiety, and (3) fear of negative evaluation. The survey was translated into 
Thai. Scores for nine statements - items 2, 5, 8, 11, 14, 18, 22 28, and 32 - which were negatively keyed for anxiety, were calculated using a 5-point scale with 1 being "strongly agree" and 5 being "strongly disagree" (e.g., Item 2 "I don't worry about making mistakes in my English class."). Scores for the remaining 24 statements, which were positively keyed for anxiety, were calculated using a 5-point scale with 1 being "strongly disagree" and 5 being "strongly agree" (e.g., Item 1 "I never feel quite sure of myself when I am speaking in my English class."). Higher scores indicated a higher level of anxiety.

The second instrument was English proficiency tests designed in parallel form covering reading and writing skills, administered as pre-test and post-test. The total score was 30 points. The contents for testing students included three main parts: 1) read a story and answer five questions, 2) read a story and write a summary in three to five sentences, and 3) write an essay in 100 words. Time allotted for both tests was 120 minutes. The items of the tests were constructed, verified for content validity by three experts, and piloted with one class in the previous semester.

The third instrument was a semi-structured interview containing two questions: 1) How do you feel about working with your partner and with the members in your group? and 2) Do you feel anxious when you study in EN211 class? Why or why not?

\subsection{Cooperative Learning Activities}

Cooperative learning activities in this study were designed and implemented in classroom based on Kagan's structure (Kagan, 1994; Kagan, 2003). The study mainly employed three activities.

The first activity called "Think-Pair-Share" involved a three-step cooperative structure. During the first step, individuals thought silently about a question posed by the instructor. Individuals paired up during the second step and exchanged thoughts. In the third step, the pairs shared their responses with other pairs, other teams, or the entire group. Students were allowed to choose their own partners in doing pair work. This kind of activity covered two tasks - dictation and writing a summary.

For a group work activity, this study employed "Numbered Heads Together." A team of four was established. Each member is given numbers of 1, 2, 3, 4. Questions were asked of the group. Groups worked together to answer the questions so that all can verbally answer them. The teacher called out a number and that number in each team was asked to give the answer. This activity was conducted to enhance students' reading comprehension skill.

The last one was "Peer Review" - an activity requiring students to read each other's draft and give comments on it. "Peer Review" provides students with the opportunity to learn how to provide and receive constructive feedback. The main goal of using peer review is to help both writers and commentators to improve their writing. The peer review in this research was conducted in pairs. The students were trained on the principles of peer correction and how to give feedback so that they would not encounter any difficulties when giving comments. Peer review training was available before the lesson officially started. This means they were taught how to follow the review procedure step-by-step, how to consult the dictionary when in doubt, how to write up a comment, etc. Giving feedback focused on the following issues: 1) clear thesis statement, 2) relevant and adequate coverage of topic focusing on central idea, 3) good supporting details, 4) coherence (transition use), 5) conveying meaning clearly and effectively, and 6) mistakes on grammatical points.

\subsection{Data Collection}

First, the participants were given the questionnaire "Foreign Language Classroom Anxiety Scale", followed by a proficiency test of which the total score was 30 . Then a 3-hour lesson was taught through cooperative learning approach for 14 weeks. The intervention was followed by the post-test and FLCAS questionnaire. The obtained scores from both instruments were compared with the previous ones to reveal changes in language performance and language anxiety. To learn how the students felt when learning with this approach, six students, whose scores improved the most and the least, were chosen to share their opinions toward this learning. 


\subsection{Data Analysis}

The data obtained from the tests and foreign language anxiety questionnaire were analyzed quantitatively using SPSS Program through descriptive and dependent t-test statistics. $\mathrm{P}$ values $<0.05$ were considered statistically significant. Also, the data from the interview were analyzed and presented.

\section{RESEARCH RESULTS}

\subsection{The Impact of Cooperative Learning on Students' Learning Anxiety}

The top five sources of foreign language classroom anxiety among the students in this study included statements $9,10,3,7$, and 20, respectively. Before the treatment, all statements were at a high level, but three from five decreased to moderate level after learning through this approach $(9,10,3)$. However, the reduction in the FLCAS mean scores of all statements reached statistical significance $(\mathrm{P}=0.00)$ as shown in Table 1.

Table 1: Pre- and Post- FLCAS Questionnaire Comparison of Top Five Sources of Anxiety

\begin{tabular}{|c|c|c|c|c|c|c|}
\hline \multirow{2}{*}{ Items } & \multicolumn{2}{|c|}{ Pre $(n=40)$} & \multicolumn{2}{|c|}{ Post $(n=40)$} & \multirow[b]{2}{*}{$\mathbf{t}$} & \multirow[b]{2}{*}{ Sig } \\
\hline & Mean & S.D. & Mean & S.D. & & \\
\hline $\begin{array}{l}\text { 9. I start to panic when I have to speak without preparation in language } \\
\text { class. }\end{array}$ & 4.22 & .66 & 3.17 & .67 & 6.41 & .000 \\
\hline 10. I worry about the consequence of failing my foreign language class. & 4.13 & 1.04 & 3.12 & .76 & 5.19 & .000 \\
\hline 3. I tremble when I know that I'm going to be called on in language class. & 4.08 & .80 & 3.35 & .80 & 4.77 & .000 \\
\hline 7. I keep thinking that other students are better at language than me. & 3.93 & .86 & 3.70 & .82 & 2.16 & .000 \\
\hline $\begin{array}{l}\text { 20. I can feel my heart pounding when I'm going to be called on in } \\
\text { language class. }\end{array}$ & 3.93 & .89 & 3.50 & .72 & 3.98 & .000 \\
\hline
\end{tabular}

The scores gained from the pre-proficiency test were used to divide the students into three groups; namely, high-, intermediate-, and low- proficiency groups using $\pm .5 \mathrm{SD}$ technique. The mean score of the pre-test was 13.55 with 5.39 SD value. So, the students whose scores fell between 10.87 and 16.23 were the intermediate group; 16.24 to highest scores were the high group; and lowest to 10.86 scores were the low group. Language anxiety in each group is presented in Table 2 below.

Table 2: Mean and Standard Deviation of Students' Language Anxiety in Three Groups

\begin{tabular}{|l|c|c|}
\hline \multicolumn{1}{|c|}{ Group } & \multicolumn{2}{|c|}{ Classroom Language Anxiety } \\
\hline & Mean & S.D. \\
\hline High Proficient $(\mathrm{n}=12)$ & 3.47 & .45 \\
\hline Intermediate Proficient $(\mathrm{n}=13)$ & 3.33 & .52 \\
\hline Low Proficient $(\mathrm{n}=15)$ & 3.36 & .48 \\
\hline
\end{tabular}

To find out whether there were any differences of students' learning anxiety among three proficiency groups at both times of the survey, the mean scores were compared using one-way ANOVA. The results show that anxiety of the three groups was not significantly different at the 0.05 level at both times (Tables 3 and 4 ).

Table 3: A Comparison of Mean Scores of Anxiety Among Three Groups Obtained from the Pre- FLCAS Questionnaire

\begin{tabular}{|l|c|c|c|c|c|}
\hline & SS & df & MS & F & Sig \\
\hline Between Groups & .137 & 2 & .069 & .294 & .747 \\
\hline Within Groups & 8.655 & 37 & .234 & & \\
\hline Total & 8.792 & 39 & & & \\
\hline
\end{tabular}


Table 4: A Comparison of Mean Scores of Anxiety Among Three Groups from Post-FLCAS Questionnaire

\begin{tabular}{|l|c|c|c|c|c|}
\hline & SS & df & MS & F & Sig \\
\hline Between Groups & .053 & 2 & .026 & .148 & .863 \\
\hline Within Groups & 6.607 & 37 & .179 & & \\
\hline Total & 6.660 & 39 & & & \\
\hline
\end{tabular}

To find out whether cooperative learning had an impact on students' learning anxiety, the mean scores obtained from the learning anxiety scale questionnaires were compared by using a paired samples t-test. The results indicate that the post-questionnaire mean score was lower than that obtained from the pre-questionnaire. This means that the students' anxiety reduced after learning with cooperative learning (Table 5).

Table 5: A Comparison of the Students' Anxiety Between the Pre- and Post- FLCAS Questionnaires

\begin{tabular}{|c|c|c|c|c|c|}
\hline & $\mathbf{N}$ & $\bar{X}$ & S.D. & t & Sig \\
\hline Pre & 40 & 3.38 & .47 & \multirow{2}{*}{$6.60 *$} & .000 \\
\hline Post & 40 & 3.24 & .42 & & \\
\hline
\end{tabular}

In order to find out whether the students' anxiety decreased significantly in each group, the pre-and postquestionnaire mean scores were compared by using a paired samples t-test. Table 6 shows that the mean scores of the post-questionnaire in three groups were lower than that of the pre-questionnaire. As evidenced by the significant difference at the level of .001 for intermediate group and at the level of .01 for high and low groups, it clearly illustrates that cooperative learning helped students to have lower anxiety (Table 6).

Table 6: The Mean Scores Obtained from Pre-and Post-FLCAS Questionnaire Shown in Three Groups

\begin{tabular}{|l|c|c|c|c|c|}
\hline \multicolumn{1}{|c|}{ Group } & N & Mean & S.D. & t-value & Sig \\
\hline High Proficient & & & & & \\
\hline Pre-test & 12 & 3.47 & .45 & .41 & \\
\hline Post-test & 12 & 3.28 & .38 & & \\
\hline Difference & & .19 & & & \\
\hline Intermediate Proficient & & & & & \\
\hline Pre-test & 13 & 3.33 & .52 & 5.23 & \\
\hline Post-test & 13 & 3.19 & .50 & & \\
\hline Difference & & .14 & & & \\
\hline Low Proficient & & & & & \\
\hline Pre-test & 15 & 3.36 & .54 & & \\
\hline Post-test & 15 & 3.23 & .32 & & \\
\hline Difference & & .13 & & & \\
\hline
\end{tabular}

\subsection{The Impact of Cooperative Learning on English Language Proficiency}

To find out whether the students improved significantly in their English proficiency, the pre- and post-test mean scores were compared by using a paired samples t-test. Table 7 shows that the mean score of the post-test was higher than that of the pre-test. As evidenced by the significant difference at the level of .001, it clearly illustrates that the cooperative learning approach used in class proved rather effective.

Table 7: A Comparison of Mean Scores of Pre-and Post-Tests

\begin{tabular}{|c|c|c|c|c|c|}
\hline & $\mathbf{N}$ & $\bar{X}$ & S.D. & t & Sig \\
\hline Pre-test & 40 & 13.55 & 5.39 & \multirow{2}{*}{$14.07 *$} & .000 \\
\hline Post-test & 40 & 18.52 & 4.16 & & \\
\hline
\end{tabular}




\subsection{The Students' Opinions on Cooperative Learning}

To learn how the students felt about learning through cooperative activities, the data were collected from six students through an interview. When asked about feelings of working with their peers, all of them were impressed and happy because of the supportive environment. The English class became more interesting. It was determined that four out of six students like "Think-Pair-Share" the most because in the pair work, they could work with more relaxation and fun. The low proficient students would contribute less to the discussion. They knew that even though they did not speak, their partner would; however, they shared the final answer. Regarding learning anxiety in class, all students said that they did not feel anxious at all. Although the students were asked to answer questions, they didn't feel worried about their low English proficiency or didn't fear making mistakes because the activity called "Numbered Heads Together" was like playing a game. Everyone helped each other to find the answer; so if one of them was called, he/she didn't have to worry about it. They felt relieved that they were not alone in a difficult situation. Three out of six students reported positive benefits from their participation in this research. They stated that it's lucky to be in this section and they were happy when they joined the activities provided. They learned that teachers can help them reduce language anxiety, so they hoped that there would be these activities in other courses too.

\section{DISCUSSION AND CONCLUSION}

The findings of the study support the use of cooperative learning as part of the language learning method due to students' anxiety reduction and higher language proficiency. The reason why their anxiety reduced was probably because this learning environment provided opportunities for students to support, encourage, and praise each other. In such an atmosphere, students may feel more comfortable to try out new ideas. The result was in accordance with Young (1999) who found that pair and small group work could contribute to a low-anxiety classroom situation. From the findings, it was determined that the pleasant atmosphere can be created by the teacher and foreign language learning anxiety is not something to be ignored or considered a problem for the students to deal with on their own. It's the teacher's task to find techniques or methods that don't cause any anxiety in class in order to help the students achieve their learning goals. Moreover, the significant improvement on the participants' language proficiency possibly resulted from the fact that discussing, creating, and thinking in a group, rather than in a whole class context, can provide a less anxiety-producing context. If group mates feel positively interdependent with one another, a supportive atmosphere can develop their learning too (Johnson \& Johnson, 1995). The language development may be due to the fact that students felt more relaxed in this learning environment. This result can be supported by many previous research results showing that cooperative learning can contribute to the improvement of students' language proficiency (Somapee, 2002; Seetapee, 2003; Lapsopa, 2005; and Nakahashi, 2007).

\section{RECOMMENDATIONS FROM THE RESEARCH}

Teachers need to pay more attention to students' learning anxiety in EFL classes and should create a low stress, friendly and supportive learning environment. Apart from cooperative learning approach, some other techniques dealing with anxiety should be investigated for their effectiveness. In addition, a study of strategies to cope with foreign language anxiety employed by students should be conducted to see if they can help reduce the learning anxiety.

\section{AUTHOR INFORMATION}

Assoc. Prof. Saovapa Wichadee is now working as a full-time teacher at the Language Institute, Bangkok Unviersity, Thailand. Her research interest includes teaching methodology in EFL and teacher self-development. She has experienced in writing many textbooks and instructional materials, such as Writing for Business Purposes, English for Art and Design, and Business Conversation.

Miss Ornprapat Suwantarathip is currently teaching at the Language Institute, Bangkok University, Thailand. Her particular field of interest lies in doing research on business writing and reading. 


\section{REFERENCES}

1. Horwitz, E., Horwitz, M., \& Cope, J. (1986). Foreign language classroom anxiety. The Modern Language Journal, 70 (2), 125-132.

2. Johnson, D. W., Johnson, R. T., \& Holubec, E. J. (1995). Circles of Learning. (4th ed.). Edina, MI: Interaction Book Company.

3. Kagan, Spencer. (1994). Cooperative Learning. San Clemente, CA: Kagan Publishing.

4. Kagan, Spencer. (2003). A brief history of Kagan structures. Kagan Online Magazine. (Summer). www.kaganonline.com/KaganClub/FreeArticles.

5. Kondo, S., \& Yang, Y-L. (2003). The English language classroom anxiety scale: Test construction, reliability, and validity. JALT Journal, 25 (2),

6. Lapsopa, Benja. (2005). A study of English reading and writing achievement of sixth grade students taught by the cooperative learning approach. M.A. Thesis, Silapakorn Unviersity.

7. MacIntyre, P. D. (1995). How does anxiety affect foreign language learning: A reply to sparks and Ganschow. The Modern Language Journal, 79(1), 90-99.

8. Nakahashi, Terri Lee. (2007). Techniques for Reducing Foreign Language Anxiety: Results of a Successful Intervention Study. (Online). http://air.lib.akitau.ac.jp/dspace/bitstream/10295/547/3/kk9-6.pdf retrieved August 12, 2010.

9. Saguanpong, S. (2007). The relationship between learning anxiety and in English classroom and the English proficiency of Thai vocational students. M.A. Thesis. Thammasat University.

10. Seetape, N. (2003). Effects of cooperative learning on English reading achievement and learning behaviors of University. M.A. Thesis, Kasetsart University.

11. Somapee, S. (2002). The effectiveness of using cooperative learning to enhance students' critical thinking skills in business English I at Chiangrai commercial school in Chiangrai. M.A. Thesis, Payap University.

12. Young, D. J. (Ed.) (1999). Affect in Foreign Language and Second Language Learning: A Practical Guide to Creating a Low-anxiety Classroom Atmosphere. Boston: McGraw-Hill College.

13. YU-ching, Daniel, \& Wu, Guo-cheng. (2004). A study of foreign language anxiety of EFL elementary school students in Taipei. County Journal of National Taipei Teachers College, September, 17(2), 287-320.

14. Worde, R. (2003). Students' perspectives on foreign language anxiety. Retrieved on Dec. 4 from http://www.vccaedu.org/inquiry/inquiry-spring2003/i-81-worde.html. 


\section{NOTES}

